Anthropos: Jurnal Antropologi Sosial dan Budaya (Journal of Social and Cultural Anthropology)

7 (1) (2021): 28-35, DOI: 10.24114/antro.v7i1.24265

Anthropos: Jurnal Antropologi Sosial dan Budaya (Journal of Social and Cultural Anthropology)

Available online http://jurnal.unimed.ac.id/2012/index.php/anthropos

\title{
Implementasi Hubungan Ilmu, Budaya, dan Ekonomi pada Lembaga Pendidikan Islam Indonesia
}

\section{Implementation of the Relationship between Science, Culture and Economics in Indonesian Islamic Education Institutions}

\author{
Ahmad Bilal Almagribi* \& Muslimah \\ Magister Ekonomi Syariah, Pascasarjana, Institut Agama Islam Negeri Palangka Raya, \\ Indonesia
}

Diterima: 08 April 2021; Direview: 08 April 2021; Disetujui: 08 Mei 2021

\begin{abstract}
Abstrak
Penelitian ini dimaksudkan untuk menemukan hubungan antara ilmu, budaya, dan ekonomi serta implementasinya pada lembaga pendidikan Islam (LPI). Metode yang digunakan adalah deskriptif kualitatif dengan kajian pustaka. Hasil penelitian menunjukkan hubungan antara ilmu, budaya, dan ekonomi berdasarkan terori unsur budaya Koentjaraningrat merupakan hubungan umum dan khusus, unsur sistem pengetahuan sama dengan ilmu dan sistem mata pencaharian sama dengan ekonomi. Ketujuh unsur budaya telah diimplementasikan dalam LPI: (1) Unsur bahasa yang digunakan adalah bahasa Indonesia, bahasa daerah, Arab, Inggris, dan bahasa asing lainnya. (2) Unsur sistem pengetahuan pada LPI condong kepada aliran tradisionalis atau modernis. (3) Unsur organisasi sosial yang ada pada LPI bisa berada di bawah pemerintah atau yayasan dengan setiap lembaga mempunyai tingkatan anggota. (4) Unsur teknologi yang dimiliki LPI terdiri dari laboratorium dengan berbagai jenisnya dan fasilitas yang kualitasnya berbeda pada setiap lokasi. (5) Unsur mata pencaharian pada LPI berupa iuran wajib, donasi, baitul mal, koperasi, atau penyewaan lapak usaha. (6) Unsur religi pada setiap LPI tentu saja berdasar pada ajaran Islam dengan memberikan kesempatan kepada nonmuslim untuk belajar pada beberapa perguruan tinggi Islam. (7) Unsur seni yang diimplementasikan LPI antara lain seni kaligrafi, rebana, membaca Al-Qur'an, khitobah, dan nasyid.

Kata kunci: Ilmu, Budaya, Ekonomi, Implementasi, Lembaga Pendidikan Islam.
\end{abstract}

\begin{abstract}
This research is intended to find the relationship between science, culture, and economics as well as their implementation in Islamic education institutions (IEI). The method used is descriptive qualitative with literature review. The results showed that the relationship between science, culture and economy based on Koentjaraningrat's cultural elements theory is general and specific, the elements of the knowledge system are the same as science and the livelihood system is the same as the economy. The seven elements of culture have been implemented in the IEI: (1) The language elements used are Indonesian, regional languages, Arabic, English, and other foreign languages. (2) The elements of the knowledge system in the IEI are leaning towards traditionalist or modernist currents. (3) The social organization elements in the IEI can be under the government or foundations with each institution having a member level. (4) Elements of technology owned by IEI consist of laboratories of various types and facilities of different quality at each location. (5) The element of livelihood at IEI is in the form of compulsory contributions, donations, baitul mals, cooperatives, or rental of business stalls. (6) The religious element in each IEI is of course based on Islamic teachings by providing opportunities for non-Muslims to study at several Islamic universities. (7) Art elements implemented by the IEI include calligraphy, tambourine, reading the Qur'an, speech, and nasheed.

Keywords: Science, Culture, Economy, Implementation, Islamic Education Institution.
\end{abstract}

How to Cite: Almagribi, A. B., \& Muslimah, M. (2021). Implementasi Hubungan Ilmu, Budaya, dan Ekonomi pada Lembaga Pendidikan Islam Indonesia. Anthropos: Jurnal Antropologi Sosial dan Budaya (Journal of Social and Cultural Anthropology), 7 (1): 28 - 35

*Corresponding author: ISSN 2549-1660 (Print)

E-mail: abalmagribi@gmail.com

ISSN 2550-1305 (Online) 


\section{PENDAHULUAN}

Ilmu, budaya, dan ekonomi merupakan tiga hal yang tak dapat dilepaskan dari kehidupan setiap manusia. Manusia yang berakal sehat setidaknya mempunyai dasar-dasar ilmu pengetahuan, terlepas ia pernah menimba ilmu di lembaga pendidikan atau hanya belajar dari lingkungan sekitar. Manusia juga secara sadar atau tidak, pasti mengikuti budaya tertentu. Misalnya saja bahasa, dipastikan semua manusia yang normal menggunakan bahasa tertentu yang sama dengan orang lain di suatu komunitas. Di sisi ekonomi, seorang manusia sebagai makhluk sosial tentu akan melakukan produksi dan konsumsi dalam berbagai bentuknya untuk memenuhi kebutuhannya.

Subroto (2014) sudah membahas tentang hubungan ekonomi dan pendidikan. Mustonah (2017) sudah membahas tentang pendidikan Islam berbasis multikultural di tingkat sekolah. Sementara Riyadi (2019) sudah membahas tentang manajemen diversity (perbedaan) dan equity (persamaan) di lembaga pendidikan Islam. Sejauh penelususan penulis, belum ada karya tulis ilmiah yang membahas ketiga hal ini secara bersamaan dalam ruang lingkup implementasinya di lembaga pendidikan Islam. Oleh karena itulah, penulis menyusun penelitian ini dengan tujuan mendeskripsikan implementasi hubungan antara ilmu, budaya, dan ekonomi dalam lembaga pendidikan Islam.

\section{METODE PENELITIAN}

Penelitian ini menggunakan metode deskriptif kualitatif desain library research dengan mengkaji berbagai literatur, dokumen, dan karya-karya lain yang berkaitan dengan permasalahan untuk dapat memaknai penelitian ini (Nawawi, 2019). Peneliti melakukan pencarian literatur berupa buku dan jurnal-jurnal ilmiah terkait implemantasi ilmu, budaya, dan ekonomi pada lembaga pendidikan
Islam di Indonesia lalu melakukan analisis deskriptif dalam penulisannya.

\section{HASIL DAN PEMBAHASAN \\ Lembaga Pendidikan Islam}

Akhiruddin (2015) membagi lembaga pendidikan Islam di Indonesia kepada empat jenis; pesantren, surau, meunasah, dan madrasah. Pesantren merupakan salah satu jenis lembaga pendidikan Islam Indonesia yang bersifat tradisional dan juga modern untuk mendalami ilmu agama Islam, dan mengimpilimentasikannya dalam kehidupan sehari-hari dengan penekanan pada moral dalam hidup bermasyarakat. Sedangkan surau adalah sebuah tempat ibadah yang pertama kali berdiri di Sumatra Barat, tepatnya di Minangkabau, yang saat ini dijadikan sebagai sarana pendidikan Islam. Lembaga pendidikan lain yang telah terbangun di Indonesia adalah meunasah. Meunasah merupakan lembaga pendidikan Islam terendah. Meunasah berasal dari kata bahasa Arab "madrasah". Meunasah itu sendiri sering dijadikan sebagai tempat upacara keagamaan, penerimaan zakat, dan kegiatan keagamaan lainnya. Lembaga pendidikan keempat adalah madrasah. Sebagaimana meunasah, madrasah juga berasal dari bahasa Arab yaitu "madrasatun" kata kerjanya "darasa" dalam bentuk "isim makan" (tempat) yang berarti tempat belajar bagi murid atau siswa.

Bafadhol (2017) mendeskripsikan lembaga pendidikan adalah lembaga atau tempat berlangsungnya proses pendidikan yang dilakukan dengan tujuan untuk mengubah tingkah laku individu ke arah yang lebih baik melalui interaksi dengan lingkungan sekitar. Ada tiga macam lembaga pendidikan Islam, yaitu: lembaga pendidikan Islam formal, nonformal, dan informal. Lembaga pendidikan formal adalah jalur pendidikan yang terstruktur dan berjenjang yang terdiri atas pendidikan dasar, pendidikan menengah, dan pendidikan tinggi. Sedangkan Lembaga pendidikan nonformal adalah jalur pendidikan di luar pendidikan formal yang dilaksanakan secara terstruktur dan berjenjang. Lembaga pendidikan nonformal ini disediakan bagi 
warga yang tidak sempat mengikuti atau menyelesaikan pendidikan pada jenjang tertentu dalam pendidikan formal. Sedangkan lembaga pendidikan informal adalah pendidikan yang ruang lingkupnya lebih terarah pada keluarga dan masyarakat. Pendidikan keluarga adalah pendidikan pertama dan utama. Keluarga merupakan lembaga pendidikan yang pertama, tempat peserta didik pertama kali menerima pendidikan dan bimbingan dari orangtuanya atau anggota keluarga yang lain. Keluargalah yang meletakkan dasar-dasar kepribadian anak. Masjid juga merupakan salah satu lembaga pendidikan Islam yang memiliki fungsi penting. Di masjid inilah kaum muslimin dididik supaya memegang teguh nilai-nilai keimanan, cinta kepada ilmu pengetahuan, mempunyai kesadaran bersosial (ukhuwwah islamiyyah) serta merealisasikan ketaatan kepada Allah dan Rasul sallallahu alaihi wasallam.

Lembaga pendidikan Islam dalam perjalanan sejarah bangsa Indonesia melalui perjuangan yang panjang dan melelahkan. Pada zaman penjajahan, berbagai cara dilakukan sebagai upaya frontal dari Belanda untuk menghentikan pendidikan Islam yang berkembang di beberapa lembaga pendidikan Islam yang pada saat itu dibentuk oleh pesantren dan madrasah. Kemudian hasil perkembangannya menjadi dikotomi institusi pendidikan di Indonesia. Banyak upaya yang dilakukan oleh kolonial Belanda untuk menghentikan proses pembelajaran di lembaga pendidikan Islam yang menanut sistem pesantren dan madrasah. Upaya ini antara lain pendirian Priesnterraden, pengawasan ketat prosesi pendidikan di lembaga pendidikan Islam; kemudian menerbitkan peraturan guru dan sekolah liar, serta upaya lain (Rahman, 2018).

Saat ini lembaga pendidikan Islam formal yang diakui pemerintah Republik Indonesia untuk jenjang dasar hingga menengah akhir menggunakan beberapa nama, antara lain: pondok pesantren (ponpes), madrasah, dan sekolah Islam. Adapun di jenjang perguruan tinggi relatif tidak terdapat perbedaan nama dengan lembaga lain, sama-sama menggunakan nama sekolah tinggi, institut, dan universitas.

\section{Hubungan Budaya, Ilmu, dan Ekonomi}

Koentjaraningrat menyatakan bahwa ada tujuh unsur kebudayaan, yaitu: bahasa, sistem pengetahuan, organisasi sosial, sistem teknologi, sistem mata pencaharian, sistem religi, dan kesenian (Dwiyanti \& Suherman, 2019). Jika mengacu pada teori unsur budaya Koentjaraningrat ini, maka ilmu dan ekonomi merupakan unsur kebudayaan. Ilmu sebagai sistem pengetahuan dan ekonomi sebagai sistem mata pencaharian. Penerapan secara rinci pada lembaga pendidikan Islam ditinjau dari ketujuh unsur budaya adalah sebagai berikut:

Unsur Bahasa. Membahas implementasi bahasa sebagai unsur budaya di lembaga pendidikan Islam, yang menjadi ciri khasnya adalah bahasa Arab. Kemahiran seseorang dalam suatu bahasa tidak menjamin kemahirannya mengajarkan bahasa tersebut kepada orang lain. Mahir berbahasa satu hal dan mahir mengajarkan bahasa adalah hal yang lain. Seorang guru bahasa Arab harus menguasai setidak-tidaknya tiga hal yaitu, (1) kemahiran berbahasa Arab, (2) pengetahuan tentang bahasa dan budaya Arab, (3) keterampilan mengajarkan bahasa Arab. Selain itu guru bahasa Arab juga harus mengetahui bahwa pembelajaran bahasa asing melibatkan sekurang-kurangnya tiga disiplin ilmu, yakni (a) linguistik, (b) psikologi, dan (c) ilmu pendidikan (Masnun, 2018). Bahasa Arab juga diajarkan dengan kurikulum yang terintegrasi dengan materi pembelajaran Islam yang lain di wilayah minoritas muslim, Provinsi Papua Barat (Wekke, 2015).

Melalui pendidikan, pesantren hadir tidak saja sebagai lembaga keagamaan, tetapi kemudian menjadi pionir di masyarakat. Kehadirian tradisi pembelajaran bahasa secara modern yang diperkenalkan Gontor tidak saja berlangsung di Pondok Modern Darussalam Gontor saja, tetapi ini menyebar menjadi sebuah lokomotif pembelajaran bahasa Arab dan Inggris di seluruh Indonesia, bahkan 
menjangkau Malaysia, Brunei Darussalam, Thailand, dan Singapura. Termasuk di dalamnya disebarkan melalui jaringan alumni Gontor atau pondok yang memang secara khusus belajar untuk mengadopsi sistem Gontor (Wekke \& Busri, 2016). Di Pondok Pesantren Putra Ta'mirul Islam Surakarta model pembelajaran bahasa Inggris yang digunakan adalah 'metode tentara', yaitu metode yang menekankan pada disiplin tinggi dan otoritas guru serta metode langsung yang menekankan pada instruksi guru (Risdianto, 2016).

Penulis telah menelusuri website Badan Akreditasi Nasional Perguruan Tinggi dan coba mengetikkan kata "Islam" pada kolom institusi dan kata "bahasa" pada kolom program studi (prodi). Hasilnya diperoleh 248 prodi bahasa, yang terdiri dari bahasa Indonesia, Arab, dan Inggris saja. Peneliti kembali menelusuri kata kunci "Muhammadiyah" dan "bahasa" lalu menemukan 128 prodi bahasa. Selain ketiga bahasa sebelumnya, terdapat 2 prodi bahasa Jepang, 1 prodi bahasa Daerah, dan secara spesifik 1 prodi bahasa Jawa yang diajarkan pada perguruan tinggi Muhammadiyah (BANPT, 2020). Tentu masih banyak lagi perguruan tinggi Islam yang tidak menggunakan kata "Islam" maupun "Muhammadiyah" dalam Namanya.

Secara umum bahasa asing yang diajarkan pada lembaga-lembaga pendidikan Islam adalah bahasa Arab dan Inggris. Bahasa Arab jelas karena merupakan bahasa Al-Qur'an yang merupakan kitab suci umat Islam. Sedangkan bahasa Inggris sudah menjadi mata pelajaran wajib bagi semua sekolah, karena masuk dalam ujian nasional (UN). Bahasa Jepang menjadi prodi pada 2 institusi pendidikan Muhammadiyah. Adapun bahasa asing lain seperti bahasa Cina, Turki, Jerman, Prancis juga diajarkan di beberapa perguruan tinggi Islam, namun hanya sebagai mata kuliah, tidak menjadi jurusan atau program studi. Ada pula sekolah atau perguruan tinggi yang hanya menjadikan bahasa asing selain bahasa Inggris dan Arab sebagai program ekstrakurikuler.

Adapun bahasa yang digunakan seharihari lembaga pendidikan Islam selain bahasa
Indonesia mengacu pada lokasi di mana lembaga itu berada dan peraturan yang diterapkan. Pondok pesantren yang berlokasi di Jawa misalnya, tak jarang kiai atau guru menjelaskan isi kitab kuning dengan bahasa Jawa. Demikian pula pondok pesantren atau perguruan tinggi yang terletak di Kalimantan Selatan misalnya, tak jarang materi pelajaran dijelaskan dengan bahasa Banjar disertai dialek lokal. Namun ada beberapa lembaga pendidikan Islam yang tidak terpengaruh wilayah dengan menggunakan bahasa daerah, karena menerapkan aturan bahwa santri tidak boleh berbicara kecuali dengan bahasa Arab atau bahasa Inggris.

\section{Unsur Sistem Pengetahuan.}

Fazlurrahman dalam Saihu (2020) merumuskan konsep pembaharuan sistem pengetahuan dalam pendidikan Islam yang melibatkan tiga pendekatan, yaitu: a) Mengislamkan pendidikan sekuler modern; b) Menyederhanakan silabus-silabus dalam rangka pendidikan tradisional; c) Menggabungkan cabang-cabang ilmu pengetahuan. Melalui tiga pendekatan ini, Fazlurrahman berargumen bahwa pendidikan Islam akan semakin berkembang dan individuindividu muslim dapat terhidar dari (split personality) atau pribadi-pribadi yang terpecah-pecah.

Sistem pengetahuan pada lembaga pendidikan Islam berbeda-beda sesuai pendiri atau pengajar yang ada di dalamnya. Jika pimpinan dan para pengajar berganti, maka pada generasi kemudian bisa saja terjadi perubahan haluan pemikiran di lembaga tersebut. Ada lembaga yang lebih condong pada pemikiran Barat, ada yang lebih banyak menyerap pemikiran Timur Tengah, dan ada yang mencoba mengkombinasikan keduanya dengan nilai-nilai budaya nusantara.

Unsur Organisasi Sosial. Universitas Muhammadiyah Aceh (UNMUHA) sebagai salah satu lembaga pendidikan tinggi yang bernaung di bawah payung Persyarikatan Muhammadiyah memiliki kepribadian yang nilai-nilainya diturunkan dari nilai ajaran Islam berlandaskan Al-Qur'an dan Hadis sebagaimana termaktub dalam anggaran dasar 
dan anggaran rumah tangga Muhammadiyah. Namun demikian, sebagai sebuah lembaga pendidikan yang diberi wewenang khusus menangani masalah pendidikan, maka UNMUHA menjadi subsistem dalam organisasi Muhammadiyah yang juga harus memilki sistem makna bersama yang dianut untuk menjalankan aktifitas organisasinya secara mandiri yang dikenal dengan budaya organisasi (Yamin, 2017).

Tidak berbeda dari lembaga pendidikan lainnya, lembaga pendidikan Islam juga ada yang berdiri di bawah pemerintah dengan status negeri dan ada pula yang dibagun oleh organisasi atau yayasan sehingga berstatus swasta. Setiap lembaga pendidikan Islam mempunyai pimpinan dengan berbagai macam istilah, seperti: mudir, pengasuh, pimpinan, kepala, atau rektor. Kemudian setiap lembaga terdiri dari beberapa cabang yang juga memiliki pimpinan. Ada yang disebut dekan, ketua, atau kepala bagian tertentu. Para pengajar disebut kiai, ustadz, mu'allim, mudarris, atau guru. Sedangkan para pelajar dikenal dengan tilmidz, tholib, santri, atau murid.

Unsur Sistem Teknologi. Pondok pesantren dinilai oleh masyarakat umum masih tertinggal dalam penguasaan teknologi, khususnya dalam pemanfaatan teknologi informasi untuk pendidikan. Padahal, potensi pembenahan ada ketika Undang-Undang Siskdiknas Nomor 20 Tahun 2003 Pasal 30 ayat 4 menempatkan pesantren sejajar dengan lembaga pendidikan lain di Indonesia. Pesantren kini tidak hanya diidentikkan dengan lembaga pendidikan yang mengajarkan ilmu-ilmu agama, tetapi juga mengembangkan ilmu pengetahuan umum, termasuk pemanfaatan teknologi informasi untuk pendidikan. Karenanya, pesantren tidak boleh menyia-nyiakan kesempatan ini dengan harus selalu memperbarui teknologi yang mereka gunakan. Dengan teknologi informasi, pesantren dapat terbantu dalam menyebarluaskan informasi tentang profil, kegiatan, dan manajemen sekolah dalam mengembangkan sumber daya manusia dan pendidikan (Arif, 2013).
Sebuah penelitian dilakukan untuk mengembangkan model pembelajaran kejujuran dengan menggunakan teknologi informasi dan komunikasi (TIK) di lembaga pendidikan pesantren. Hal itu juga untuk menjawab permasalahan degradasi akhlak dan etika yang baru saja dilanda pesantren akibat perubahan global yang begitu cepat, menjelang kesiapan mental manusia dalam menghadapinya. Hasil penelitian itu menyatakan bahwa metode tersebut berpengaruh sangat signifikan terhadap peningkatan sikap dan perilaku jujur (Mansur dkk., 2016).

Teknologi memiliki peran penting dalam pelaksanaan pembelajaran, khususnya pada saat pandemi COVID-19 seperti saat ini. Teknologi berperan sebagai media dalam melakukan interaksi antara pendidik dan siswa dalam pelaksanaan pembelajaran online. Dalam penyelenggaraan pembelajaran online tentunya terdapat kendala yang menjadi tantangan bagi para pelaku pendidikan, terkait budaya akademik, antara lain: nilai, sikap, pengetahuan, keterampilan, dan kesiapan sarana dan prasarana terkait teknologi. Penerapan literasi dan pelatihan terkait penggunaan teknologi dapat menjadi solusi untuk menghadapi beberapa tantangan pembelajaran online selama pandemi COVID19 saat ini (Salsabila dkk., 2020). Di antara lembaga pendidikan Islam yang menggunakan media teknologi informasi selama pandemi COVID-19 adalah MTs. PAI Medan (Lubis dkk., 2020) dan MTs Al-Asyhar Bungah Gresik (Anshori \& Illiyyin, 2020).

Teknologi yang digunakan oleh lembaga pendidikan Islam mencakup laboratorium komputer, laboratorium bahasa, laboratorium sains, fasilitas wifi, dan pembelajaran daring. Perbedaan teknologi yang dimiliki oleh lembaga pendidikan Islam tidak lepas dari faktor lokasi dan status lembaga seperti yang sudah dibahas sebelumnya. Lokasi yang dekat dengan kota besar atau lembaga negeri biasanya mempunyai fasilitas lebih baik daripada lembaga pendidikan yang jauh dari kota atau berstatus swasta. Meskipun tidak dipungkiri juga ada lembaga pendidikan 
swasta yang mempunyai kualitas teknologi lebih daripada lembaga negeri.

Unsur Sistem Mata Pencaharian. Beberapa lembaga pendidikan Islam tidak ingin hanya mengandalkan biaya SPP dari orang tua pelajar atau donasi dari para dermawan. Hingga muncullah istilah Pesantren Entrepreneur, di mana pembelajaran wirausaha masuk dalam kurikulum pesantren (Anam, 2016). Pesantren Sidogiri adalah salah satu pondok pesantren yang sukses mencetak para wirausawan muda (Ahmady, 2013) dan terkenal dengan Baitul Mal wa Tamwilnya. Ada pula pesantren yang menjalankan usahanya dengan sistem koperasi seperti di Pondok Pesantren Darussalam Dukuh Waluh, Banyumas (Sulaiman dkk., 2016).

Bahkan Pondok Pesantren Ulul Albab Cabang Sangkanhurip yang terletak di area persawahan Kabupaten Bandung ikut terlibat memberikan solusi masalah ekonomi masyarakat agar bebas dari rentenir dan dosa ribanya dengan merancang sebuah model dengan nama Kelompok Usaha Kreatif Islami (KUKIS). Program ini memberdayakan perempuan-perempuan usia produktif di lingkungan pondok pesantren. Setelah 1 bulan memulai usaha dengan model KUKIS ini, ternyata terjadi peningkatan penghasilan ratarata sebesar 18\% yaitu Rp.255.000 per warga (Widiastuti \& Kartika, 2017).

Dapat disimpulkan bahwa sistem mata pencaharian lembaga pendidikan Islam ada yang berupa iuran wajib orang tua atau wali (SPP) yang dianggap sebagai biaya jasa pengajaran atau sumbangan pembangunan, sumbangan sukarela para donatur yang dapat berupa dana zakat, infaq, sedekah, atau wakaf (ZISWAF), baitul mal, koperasi, dan toko atau kios yang disewakan lembaga pendidikan Islam kepada pengusaha atau pedagang.

Unsur Sistem Religi. Karena objek penelitian adalah lembaga pendidikan Islam, tentu saja sistem keagamaan yang dianut semua lembaga adalah berdasar pada ajaran Islam. Namun, Universitas-Universitas Muhammadiyah yang merupakan institusi pendidikan di bawah Organisasi
Muhammadiyah tetap menerima nonmuslim untuk belajar di sana. Mahasiswa selain Islam yang belajar di kampus Muhammadiyah juga akan mendapat mata kuliah Al-Islam dan Kemuhammadiyahan sebagaimana yang telah diajarkan di Universitas Muhammadiyah Malang (Isnaini, 2015) dan Universitas Muhammadiyah Sorong (Kahar \& Pabalik, 2018), demikian juga perguruan tinggi Muhammadiyah lainnya.

Lembaga pendidikan Islam pada jenjang perkuliahan tidak semuanya dikhususkan untuk umat Islam saja. Dengan demikian, layaknya mahasiswa muslim dapat belajar di universitas Kristen, mahasiswa nonmuslim pun bisa belajar di universitas Islam atau yang berada di bawah naungan organisasi Islam. Tidak ada paksaan untuk masuk Islam, namun mahasiswa nonmuslim yang berkuliah di universitas Islam tetap wajib mengikuti mata kuliah agama Islam.

Unsur Seni. Pada dasarnya Islam tidak anti dengan seni, selama wujud dari seni tersebut tidak dilarang menurut syariat Islam. Kampus Universitas Islam Negeri (UIN) Antasari yang terletak di Kota Banjarmasin Kalimantan Selatan memiliki jumlah komunitas seni sebanyak 4 dari 6 unit kegiatan mahasiswa. Terlepas pengamalan ibadah pelaku seni sanggar di UIN Antasari Banjarmasin yang sebagian besar masih belum tercapai dalam prakteknya secara maksimal, baik dari segi pelaksanaan shalat wajib lima waktu, puasa, begitu juga dari aspek aqidah, syariah, dan akhlak (Hendy, 2019).

Universitas Islam Negeri (UIN) Maulana Malik Ibrahim Malang sendiri mempunyai Unit Kegiatan Mahasiswa (UKM) yang bernama Seni Religius. UKM ini mempunyai visi utama menjadi UKM yang kompetitif dan komparatif di dunia seni yang bersifat islami dalam melakukan pendidikan, pengajaran, pelatihan, dan pengabdian di masyarakat (Albardi, 2019). Pondok Pesantren Modern Thawalib Gunung yang terletak di Kota Padang Panjang Sumatera Barat adalah salah satu pesantren yang memberikan pelatihan seni kaligrafi pada siswanya (Hanafi dkk., 2020), bahkan di Jawa Barat, pesantren berperan dalam penyebaran 
seni kaligrafi (Kusdiana, 2012). Sementara Pesantren Al-Falah Cicalengka Kabupaten Bandung melaksanaan pembelajaran seni baca Al-Qur'an yang disusun sedemikian rupa berdasarkan kemampuan santri ketika awal masuk pesantren melalui placement (penempatan), sehingga memudahkan santri maupun ustadz dalam memasuki proses pembelajaran selanjutnya (Latipah, 2011).

Di antara seni yang telah diimplementasikan pada lembaga-lembaga pendidikan Islam adalah seni menulis atu melukis kaligrafi, seni baca Al-Qur'an, nasyid, rebana, dan keterampilan pidato (khitobah).

\section{SIMPULAN}

Hubungan antara ilmu, budaya, dan ekonomi merupakan hubungan umum dan khusus jika dipandang berdasarkan terori unsur budaya Koentjaraningrat, di mana ilmu mewakili unsur sistem pengetahuan dan ekonomi mewakili sistem mata pencaharian. Implementasi ketujuh unsur budaya dalam lembaga pendidikan Islam (LPI): (1) Unsur bahasa pada LPI diimplementasikan tentu dengan menggunakan bahasa Indonesia sebagai bahasa nasional, bahasa daerah, bahasa Arab, Inggris, dan beberapa bahasa asing lainnya. (2) Unsur sistem pengetahuan LPI bervariasi sesuai pimpinan dan pengajar yang condong ke aliran Timur Tengah atau Barat. (3) Unsur organisasi sosial LPI dapat berstatus negeri atau swasta. Ada tingkat pimpinan utama, pimpinan bagian, dewan pengajar, dan pelajar. (4) Unsur teknologi LPI mempunyai beragam laboratorium dan fasilitas internet dengan kualitas berbeda sesuai status dan lokasi lembaga. (5) Unsur mata pencaharian LPI dengan iuran wajib, sumbangan sukarela, baitul mal, koperasi, atau penyewaan tempat. (6) Unsur religi LPI berasas Islam, namun nonmuslim diperkenankan belajar pada beberapa perguruan tinggi Islam. (7) Unsur seni yang diimplementasikan LPI antara lain seni membaca Al-Qur'an, khitobah, rebana, kaligrafi, dan nasyid.
Penelitian ini masih sangat terbatas, mengingat peneliti hanya meninjau hubungan dan implementasi ilmu dan ekonomi melalui unsur budaya. Maka, penelitian selanjutnya direkomentasikan untuk membahas dengan teori yang lain atau memperinci satu per satu dari setiap unsur budaya ini dan implementasinya pada lembaga pendidikan Islam Indonesia. Hal yang mungkin jarang dikaji termasuk sistem pembelajaran sekolah Indonesia di luar negeri, misalnya di negara mayoritas muslim Arab Saudi. Di mana terdapat Sekolah Indonesia Riyadh dan Sekolah Indonesia Jeddah.

\section{DAFTAR PUSTAKA}

Ahmady, N. (2013). Pesantren Dan Kewirausahaan: Peran Pesantren Sidogiri Pasuruan Dalam Mencetak Wirausaha Muda Mandiri. Peneliian Individu. http://digilib.uinsby.ac.id/6976/

Akhiruddin, K. (2015). Lembaga Pendidikan Islam di Nusantara. TARBIYA: Jurnal Ilmu Pendidikan Islam, 1(1), 195-219.

Albardi, R. (2019). Pengaruh konformitas kelompok terhadap prestasi belajar akademik mahasiswa aktif UKM Seni Religius Universitas Islam Negeri Maulana Malik Ibrahim Malang [Undergraduate, Universitas Islam Negeri Maulana Malik Ibrahim]. http://etheses.uinmalang.ac.id/15679/

Anam, S. (2016). Pesantren Entrepreneur dan Analisis Kurikulum Pesantren Mukmin Mandiri Waru Sidoarjo dalam Pengembangan Dunia Usaha. Maraji: Jurnal Ilmu Keislaman, 2(2), 304-329. https://doi.org/10.36835/maraji.v2i2.50

Anshori, I., \& Illiyyin, Z. (2020). Dampak Covid-19 Terhadap Proses Pembelajaran Di Mts Al-Asyhar Bungah Gresik. Islamic Management: Jurnal Manajemen Pendidikan Islam, 3(02), 181-199. https://doi.org/10.30868/im.v3i2.803

Arif, M. (2013). Perkembangan Pesantren Di Era Teknologi. Jurnal Pendidikan Islam, 28(2), 307322. https://doi.org/10.15575/jpi.v28i2.550

Bafadhol, I. (2017). LEMBAGA PENDIDIKAN ISLAM DI INDONESIA. Edukasi Islami: Jurnal Pendidikan Islam, 6(11), 14. https://doi.org/10.30868/ei.v6i11.95

BAN-PT, W. (2020). Direktori Hasil Akreditasi Program Studi. Badan Akreditasi Nasional Perguruan Tinggi.

https://www.banpt.or.id/direktori/prodi/penc arian_prodi.php

Dwiyanti, R., \& Suherman, A. (2019). Unsur Budaya Dalam Cerita Film Cakra Buana Karya Sutradara 
Massimo Burhanuddin. LOKABASA, 10(2), 204213. https://doi.org/10.17509/jlb.v10i2.21361

Hanafi, H.-, Ariesta, O., \& Maulana, I. (2020). Pelatihan Seni Kaligrafi Islam Di Pesantren Thawalib Gunuang. Batoboh, 5(2), 113-123. https://doi.org/10.26887/bt.v5i2.1297

Hendy, M. (2019, Januari 11). Pengamalan Ibadah Pelaku Seni Sanggar di Universitas Islam Negeri Antasari Banjarmasin. Dakwah dan Ilmu Komunikasi. https://idr.uinantasari.ac.id/11244/

Isnaini, S. U. (2015). Persepsi Mahasiswa Non Muslim Terhadap Pembelajaran Al-Islam Dan Kemuhammadiyahan Di Universitas Muhammadiyah Malang [Other, University of Muhammadiyah Malang]. http://eprints.umm.ac.id/26458/

Kahar, M. S., \& Pabalik, D. (2018). Profil Pendidikan Karakter Mahasiswa Non Muslim dalam Implementasi Al-Islam dan Kemuhammadiyahan. Al-Hayat: Journal of Islamic Education, 2(1), 79-88.

Kusdiana, A. (2012). Peran Pesantren dalam Penyebarluasan Seni Kaligrafi Islam di Jawa Barat. Panggung, 22(4), Article 4. https://doi.org/10.26742/panggung.v22i4.65

Latipah, P. (2011). Pembelajaran Seni Baca Al-Qur'an Untuk Menghasilkan Santri Yang Memiliki Kompetensi Seni Islami Di Pesantren Al Falah [Masters, Universitas pendidikan indonesia]. http://repository.upi.edu

Lubis, M., Yusri, D., \& Gusman, M. (2020). Pembelajaran Pendidikan Agama Islam Berbasis E-Learning (Studi Inovasi Pendidik MTS. PAI Medan di Tengah Wabah Covid-19). Fitrah: Journal of Islamic Education, 1(1), 1-18.

Mansur, A. H., Husaini, A., Mujahidin, E., \& Tafsir, A. (2016). Model Pengajaran Karakter Kejujuran Menggunakan Teknologi Informasi dan Komunikasi (Studi Inovasi Pembelajaran di Pondok Pesantren Al-Azhaar Lubuklinggau). Ta'dibuna: Jurnal Pendidikan Islam, 5(1), 1-24. https://doi.org/10.32832/tadibuna.v5i1.584

Masnun, M. (2018). Teori Linguistik dan Psikologi dalam Pengajaran Bahasa Arab di Lembaga Pendidikan Islam. Jurnal Pendidikan Islam, 8(1), 172-204. https://doi.org/10.38073/jpi.v8i1.107

Mustonah, S. (2017). Implementasi Pendidikan Islam Berbasis Multikultural Di Sekolah Menengah Pertama Kota Cilegon Banten. Tanzhim, 1(01), 41-48.

Nawawi. (2019). Metode Penelitian Fiqh Dan Ekonomi Syari'ah. Madani Media.

Rahman, K. (2018). Perkembangan Lembaga Pendidikan Islam di Indonesia. Tarbiyatuna: Kajian Pendidikan Islam, 2(1), 1-14.
Risdianto, F. (2016). Model Pembelajaran Bahasa Inggris Di Ponpes "Ta'mirul Islam" Surakarta (English Learning Model At "Ta'mirul Islam” Boarding House Of Surakarta). LEKSEMA: Jurnal Bahasa dan Sastra, 1(1), 47-58. https://dx.doi.org/10.22515/ljbs.v1i1.24

Riyadi, I. (2019). Manajemen Diversity dan Kesetaraan dalam Lembaga Pendidikan Islam: Suatu Analisis Realitas Sosial. MAWA'IZH: JURNAL DAKWAH DAN PENGEMBANGAN SOSIAL KEMANUSIAAN, 10(2), 231-247. https://doi.org/10.32923/maw.v10i2.883

Saihu, S. (2020). Konsep pembaharuan pendidikan islam menurut fazlurrahman. Andragogi: Jurnal Pendidikan Islam dan Manajemen Pendidikan Islam, 2(1), 82-95. https://doi.org/10.36671/andragogi.v2i1.76

Salsabila, U. H., Sari, L. I., Lathif, K. H., Lestari, A. P., \& Ayuning, A. (2020). Peran Teknologi Dalam Pembelajaran Di Masa Pandemi Covid-19. AlMutharahah: Jurnal Penelitian Dan Kajian Sosial Keagamaan, 17(2), 188-198. https://doi.org/10.46781/almutharahah.v17i2.138

Subroto, G. (2014). Hubungan Pendidikan dan Ekonomi: Perspektif Teori dan Empiris. Jurnal Pendidikan dan Kebudayaan, 20(3), 390-405. https://doi.org/10.24832/jpnk.v20i3.318

Sulaiman, A. I., Masrukin, M., Chusmeru, C., \& Pangestuti, S. (2016). Pemberdayaan Koperasi Pondok Pesantren sebagai Pendidikan Sosial dan Ekonomi Santri. JPPM (Jurnal Pendidikan dan Pemberdayaan Masyarakat), 3(2), 109-121. https://doi.org/10.21831/jppm.v3i2.11303

Wekke, I. S. (2015). Tradisi Pesantren Dalam Konstruksi Kurikulum Bahasa Arab Di Lembaga Pendidikan Minoritas Muslim Papua Barat. KARSA: Journal of Social and Islamic Culture, 22(1), 20-38. https://doi.org/10.19105/karsa.v22i1.549

Wekke, I. S., \& Busri, M. (2016). Kepemimpinan Transformatif Pendidikan Islam: Gontor, Kemodernan, dan Pembelajaran Bahasa. Deepublish.

Widiastuti, N., \& Kartika, P. (2017). Penerapan Model Kelompok Usaha Kreatif Islami (Kukis) Dalam Pemberdayaan Perempuan Berbasis Pondok Pesantren. EMPOWERMENT: Jurnal Ilmiah Program Studi Pendidikan Luar Sekolah, 6(2), 20-29.

https://doi.org/10.22460/empowerment.v6i2p 20-29.546

Yamin, M. (2017). Meneguhkan Dimensi Budaya Organisasi Universitas Muhammadiyah Aceh. Jurnal Ilmiah Manajemen Muhammadiyah, 7(1), Article 1. http://eiournal.unmuha.ac.id/index.php/iimma Larticle/view/489 

Anthropos: Jurnal Antropologi Sosial dan Budaya (Journal of Social and Cultural Anthropology) 7 (1) (2021): 28-35 